Int. J. Dev. Biol. 51: 321-325 (2007)

doi: $10.1387 / \mathrm{ijdb} .062252 \mathrm{kn}$

Short Communication

\title{
The N-terminus zinc finger domain of Xenopus SIP1 is important for neural induction, but not for suppression of Xbra expression
}

\author{
KAZUHIRO R. NITTA ${ }^{1}$, SHUJI TAKAHASHI 2,3 , YOSHIKAZU HARAMOTO ${ }^{2}$, MASAKAZU FUKUDA ${ }^{1}$, KOUSUKE \\ TANEGASHIMA ${ }^{2}$, YASUKO ONUMA ${ }^{4}$ and MAKOTO ASASHIMA $1,2,3,4,5, *$ \\ ${ }^{1}$ Department of Biological Sciences, Graduate School of Arts and Sciences, The University of Tokyo, ${ }^{2}$ Department of Life Sciences \\ (Biology), Graduate School of Arts and Sciences, The University of Tokyo, ${ }^{3}$ Center for Structuring Life Sciences, Graduate School of \\ Arts and Sciences, The University of Tokyo, ${ }^{4}$ Network for Life Science Education, The University of Tokyo, and ${ }^{5}$ ICORP Organ \\ Regeneration Project, Japan Science and Technology Agency (JST), Tokyo, Japan
}

\begin{abstract}
Smad-interacting protein-1 (SIP1), also known as $\delta E F 2, Z E B 2$ and zfhx1b, is essential for the formation of the neural tube and the somites. Overexpression of Xenopus SIP1 causes ectopic neural induction via inhibition of bone morphogenetic protein (BMP) signaling and inhibition of Xbra expression. Here, we report the functional analyses of 4 domain-deletion mutants of XSIP1. Deletion of the $\mathrm{N}$-terminus zinc finger domain suppressed neural induction and BMP inhibition, but these were not affected by deletion of the other domains (the Smad binding domain, the DNA-binding homeodomain together with the CtBP binding site and the C-terminus zinc finger). Therefore SIP1 does not inhibit BMP signaling by binding to Smad proteins. In contrast, all of the deletion constructs inhibited $X b r a$ expression. These results suggest that the $\mathrm{N}$-terminus zinc finger domain of XSIP1 has an important role in neural induction and that $\mathrm{Xbra}$ suppression occurs via a mechanism separate from the neural inducing activity.
\end{abstract}

KEY WORDS: Smad-interacting protein-1, Brachyury (T), ZEB, $\delta E F$, Zfhx1, homeodomain

\section{Introduction}

The $\delta E F 1$ family proteins, $\delta E F 1 / Z E B 1 / Z f h x 1 a$ and Smad-

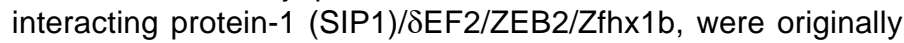
identified as transcriptional repressors (van Grunsven et al., 2001). Proteins in this family have multiple conserved domains: a homeodomain (HD), a C-terminal binding protein (CtBP) binding site (CBS) and two two-handed zinc finger domains (one at the $\mathrm{N}$ terminus, NZf; and one at the C-terminus, CZf). SIP1 also has a Smad binding domain (SBD), which interacts with regulatory Smads, the mediators of TGF- $\beta$ superfamily signaling (Funahashi et al., 1993, Verschueren et al., 1999, Yoshimoto et al., 2005).

Loss-of-function studies have shown that $\delta E F 1 / Z E B 1$ plays an essential role in skeletal formation and T-cell development (Higashi et al., 1997, Takagi et al., 1998). Biochemical studies have shown that $\delta E F 1 / Z E B 1$ represses transcription by a mechanism that involves binding of the CBS to CtBP, which recruits histone deacetylases (Chinnadurai, 2002, Furusawa et al., 1999, Postigo and Dean, 1999b). The zinc finger domains also play a role in transcriptional repression, with NZfs functioning in T lymphocytes and CZfs in muscle (Postigo and Dean, 1999a). In addition, the $\mathrm{NR}$ domain, which is closest to the $\mathrm{N}$-terminus, is required for complete repression of beta1-crystallin enhancer (Sekido et al., 1994). On the other hand, $\delta E F 1$ has been shown to function as a transcriptional activator for bone morphogenetic protein (BMP) signaling, by associating with p300 and p/CAF (Postigo et al., 2003). These findings suggest that $\delta E F 1 / Z E B 1$ has both repressor and activator functions and that the multiple domains enable it to play different roles depending upon context.

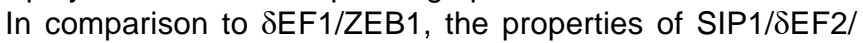
ZEB2 have been less extensively investigated. SIP1 was originally identified as a protein binding to Smad1 by screening using the yeast two-hybrid system (Verschueren et al., 1999). SIP1 represses transcription on the E-cadherin promoter, independently of CtBP binding (van Grunsven etal., 2003). Deletion of the

Abbreviations used in this paper: BMP, bone morphogenetic protein; CtBP, Cterminal binding protein; CZf, C-terminus zinc finger; HD, homeodomain; NZf, N-terminus zinc finger; SBD, smad binding domain; SIP, smadinteracting protein.

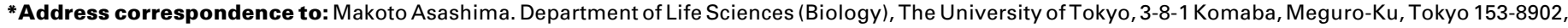
Japan. Fax: +81-3-5454-4330. e-mail: asashi@bio.c.u-tokyo.ac.jp
} 


\begin{tabular}{|c|c|c|c|c|c|}
\hline & $\mathrm{N}$-Zincfinger & $\begin{array}{c}\text { Smad binding } \\
\text { domain }\end{array}$ & $\begin{array}{l}\text { Homeo- } \\
\text { domain }\end{array}$ & $\begin{array}{l}\text { CtBP } \\
\text { site }\end{array}$ & C-Zincfinger \\
\hline & & & & & \\
\hline
\end{tabular}

myc tag

MT-XSIP

MT- $\Delta N Z f$

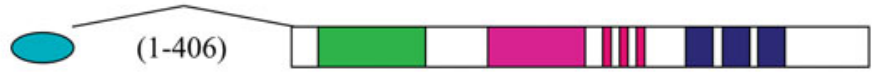

MT- $\Delta$ SBD

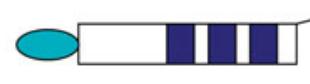

$(408-505)$

MT- $\Delta \mathrm{HD}$
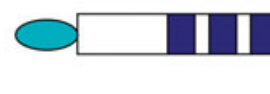

$\mathrm{MT}-\Delta \mathrm{CZf}$

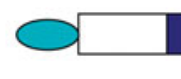

$(507-880)$

IIII

$(882-1214)$
Fig. 1. XSIP1 deletion constructs. Numbers indicate amino acid positions for deleted sequences. The stop codon of the pCS2-MT vector was used for MT-XSIP1- $\Delta$ CZf. and genes downstream of BMP signaling (Nitta et al., 2004, Postigo, 2003, van Grunsven etal., 2006). One of the genes downstream of BMP signaling is Xenopus Vent2. The promoter for Xenopus Vent2 contains an E2 box (the binding site for the $\delta \mathrm{EF} 1$ family) and is negatively regulated by SIP1 (Postigo et al., 2003). In addition, XSIP1 directly inhibits expression of the pan-mesodermal gene, Xbrachyury (Xbra) (Papin etal., 2002, van Grunsven et al., 2006). It has also been suggested that SIP1 can function as a transcription activator, based on its action on the Foxe3promoter (Yoshimoto et al., 2005). A recent study has revealed that XSIP1 associates with p300 and p/CAF (van Grunsven et al., 2006), suggesting that SIP1, like $\delta E F 1$, can act as both an activator and a repressor in a contextdependent manner.

Here we analyzed which domain of SIP1 is required for neural formation, using 4 domain-deletion mutants of XSIP1. Deletion of NZf markedly reduced the neural inducing activity of SIP1. The other mutations, including the SBD deletion, did not affect the neural inducing activity or BMP inhibitory SBD decreases repressor activity on the E-cadherin promoter (Comijn et al., 2001). Xenopus SIP1 (XSIP1) inhibits BMP signaling and drives the putative epidermis towards a neural fate (Eisaki et al., 2000, Nitta et al., 2004, van Grunsven et al., 2006). Overexpression of XSIP1 suppresses the transcription of BMP activity. In addition, all deletion mutants retained inhibitory activity against $X$ braexpression. These results suggest that the inhibitory activity of XSIP1 on BMP signaling is dependent upon the $\mathrm{N}$ terminal domain and that suppression of $X b r a$ expression caused by SIP1 is regulated by a different mechanism.
A

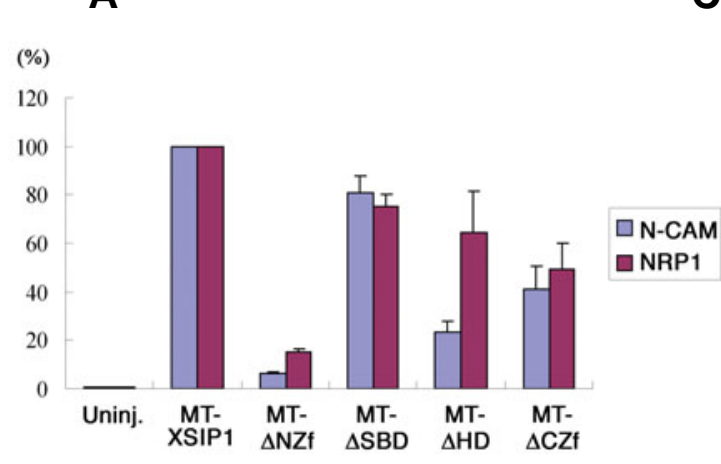

B

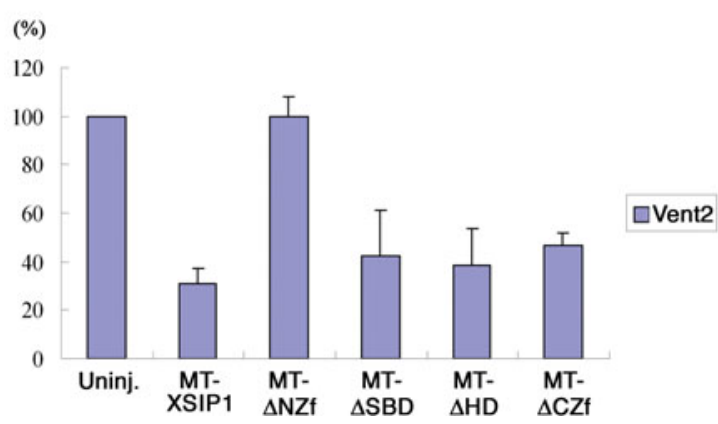

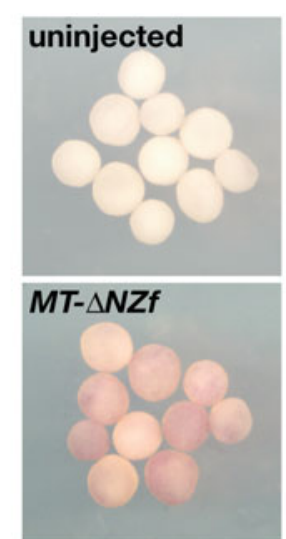
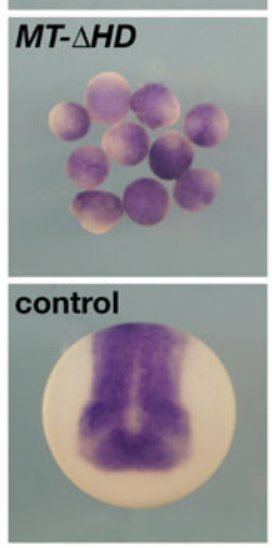

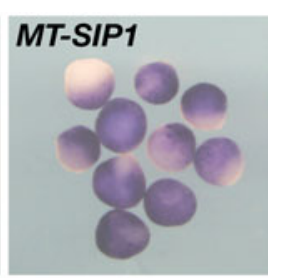

$M T-\triangle S B D$

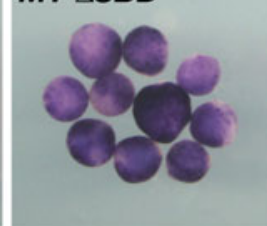

MT- $\triangle C Z f$

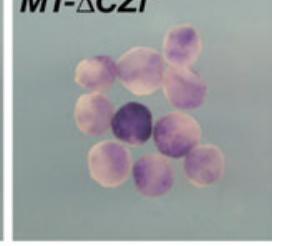
percentages relative to the expression levels in uninjected animal caps. (C) Whole-mount in situ hybridization analysis of Sox 2 expression in animal caps injected with XSIP1 deletion mutant mRNA. Animal caps were dissected from embryos injected with 500 pg XSIP1 construct mRNA and were cultured until the sibling embryos reached stage 14. The expression of Sox2 was markedly reduced in animal caps injected with MT-XSIP1- $\mathrm{NZf}$ mRNA. mount in situ hybridization analyses of animal caps injected with XSIP1 deletion mutants. (A) N-CAM and NRP1 expression levels in animal caps injected with XSIP1 construct mRNA. Animal caps were dissected from embryos injected with 500 pg of XSIP1 construct mRNA and were cultured until the sibling embryos reached stage 32. Expression of N-CAM and NRP1 mRNA was quantified by real-time RT-PCR. The results are represented as percentages relative to the expression levels in animal caps injected with MT-XSIP1 mRNA. (B) Vent2 expression levels in animal caps injected with XSIP1 construct mRNA. Animal caps were dissected from embryos injected with 500 pg of XSIP1 deletion mutant mRNA and were cultured until the sibling embryos reached stage 11. Expression of Vent2 mRNA was quantified by real-time RT$P C R$. The results are represented as

Fig. 2. Real-time RT-PCR and whole- 


\section{Results and Discussion}

\section{Deletion of N-terminus containing NZf changes the function of XSIP}

To investigate the function of each conserved domain of SIP1, we generated 4 domain-deletion constructs of XSIP1. These corresponded to 4 conserved domains of SIP1: (1) the NZf, (2) the SBD, (3) the HD and CBS together (HD-CBS) and (4) the CZf (Fig. 1). All constructs were tagged with 6 myc epitopes on the $\mathrm{N}$ terminus to confirm the protein expression. We confirmed that the myc-tagged XSIP1 (MT-XSIP1) had neural inducing activity that was equivalent to XSIP1, indicating that the introduced myc-tag did not affect the function of the protein (data not shown).

We first examined the activity of each deletion construct on neural induction. All myc-tagged constructs were overexpressed in animal caps and the expression levels of the neural differentiation markers, $N$-CAMand NRP1, were analyzed by real-time RTPCR (Fig. 2A). While MT-XSIP1 and MT-XSIP1- $\triangle$ SBD induced the expression of $N-C A M$ and $N R P 1$, MT-XSIP1- $\triangle \mathrm{NZf}$ showed marked loss of activity. Overexpression of MT-XSIP1- $\triangle$ HD-CBS and MT-XSIP1- $\Delta$ CZf also resulted in weaker expression of these markers, in comparison with MT-XSIP1.

Inhibition of BMP signaling results in neural induction, so we next investigated the expression levels of Vent2, a gene downstream of BMP signaling that is directly regulated by XSIP1 (Postigo et al., 2003). When BMP was overexpressed in animal caps, Vent2 expression was induced (Fig. 2B). MT-XSIP1- $\Delta$ NZf did not suppress the expression of Vent2, whereas MT-SIP1 and the other 3 deletion constructs did inhibit Vent2 expression.

We also evaluated the function of NZf on neural induction by in situ hybridization of animal caps (Fig. 2C). All 5 constructs were overexpressed in animal caps, followed by in situhybridization for the neural marker gene, Sox2(Kondoh et al., 2004, Sasai, 2001). Consistent with the results using real-time RT-PCR, deletion of $\mathrm{NZf}$ caused the loss of Sox2induction, while activity was retained by the other deletion constructs. These results indicate that NZf is required for both neural induction and suppression of BMP signaling, whereas the other conserved domains of XSIP1 (SBD, $\mathrm{HD}, \mathrm{CBS}$ and CZf) are not essential for these activities in animal caps. In addition, although SIP1 was originally identified as a protein that interacts with Smad proteins, these findings indicate that binding to Smad1 is not important for these activities of XSIP1. It has been reported that the zinc-finger clusters of the $\mathrm{N}$ terminal and $\mathrm{C}$-terminal regions of $\delta \mathrm{EF} 1$ directly bind to the $\mathrm{E} 2$ box sequence and that the NR domain in the $\mathrm{N}$-terminal region acts as an active repressor to silence the enhancer (Postigo and Dean, 1999a, Sekido et al., 1994). The NR domain in the Nterminal region is also conserved in XSIP1, suggesting that XSIP1 works as an active repressor of genes downstream of BMP signaling.

\section{Inhibition of Xbra expression is not affected by deletion of any single domain}

In addition to inhibition of BMP signaling and neural induction, XSIP1 directly represses endogenous Xbraexpression (Papin et al., 2002, van Grunsven et al., 2006). Xbra expression is induced by Nodal/Smad2 signaling and FGF signaling (Agius et al., 2000, Amaya et al., 1991, Eimon and Harland, 1999, Onuma et al., 2002, Takahashi et al., 2000, Tanegashima et al., 2000). To
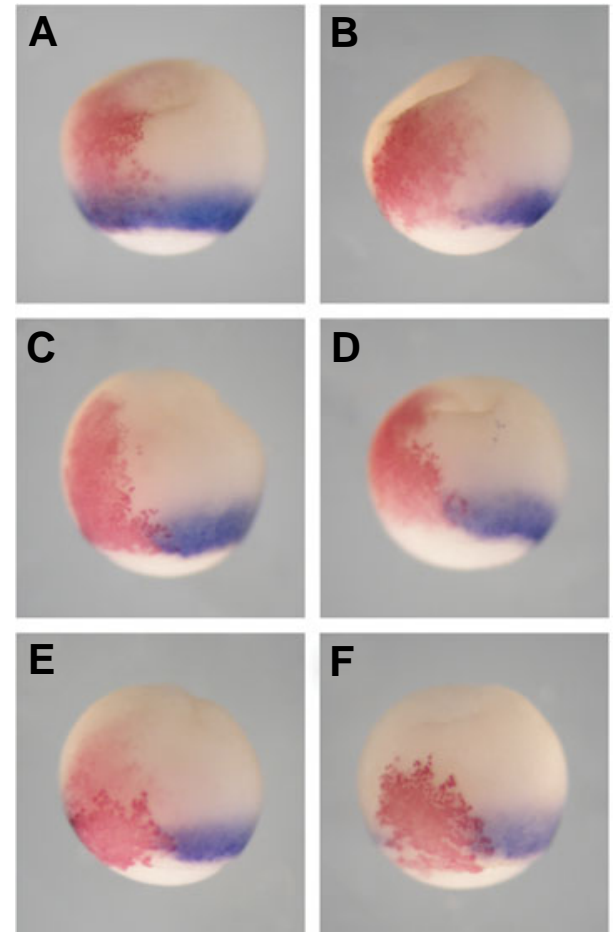

Fig. 3. Xbra expression was downregulated by overexpression of XSIP1 deletion mutants. Each mRNA (500 pg) was co-injected with lacZ $m R N A$ into the marginal region of one blastomere of 4-cell-stage embryos. The injected embryos were cultured until the sibling embryos reached stage 11. Xbra expression was downregulated in the region where mRNA was injected (marked by Red-Gal staining). The embryos shown were injected with lacZ alone (A), MT-SIP1 (B), MT- $\Delta \mathrm{NZf}$ (C), MT$\Delta$ SBD (D), MT- $\Delta$ HD-CBS (E), or MT- $\Delta$ CZf (F).

investigate the contribution of each conserved domain of SIP1 on repression of $X b r a$ expression, we carried out whole-mount in situ hybridization analysis on embryos overexpressing the 4 deletion mutants (Fig. 3). All embryos that were injected with MT-XSIP1 mRNA showed suppression of Xbra expression on the side of injection ( $n=66)$ (Fig. 3B). Expression of Xbrawas also inhibited in every embryo injected with one of the 4 domain-deletion mutants (MT-XSIP1- $\Delta$ NZf, $n=62$; MT-XSIP1- $\triangle$ SBD, $n=66$; MTXSIP1- $\Delta$ HD-CBS, $n=61$; MT-XSIP1- $\Delta$ CZf, $n=68$; Fig. 3C-F). These results indicate that no single functional domain of SIP1 is responsible for suppression of Xbra expression and that multiple domains may be independently involved in Xbrasuppression. Our findings also suggests that SIP1 suppresses Xbra expression by a mechanism that is different from suppression of BMP signaling.

\section{Experimental Procedures}

\section{Embryos}

Xenopus laevis embryos were obtained by artificial fertilization and were cultured in $10 \%$ Steinberg's solution (SS) at $20^{\circ} \mathrm{C}$. Embryos were staged according to Nieuwkoop and Faber (Nieuwkoop and Faber, 1956).

\section{Plasmid constructs}

The plasmids pCS2-MT-XSIP1, pCS2-MT-XSIP1- $\mathrm{NZf}$, pCS2-MTXSIP1- $\triangle$ SBD, pCS2-MT-XSIP1- $\Delta$ HD-CBS and pCS2-MT-XSIP1- $\Delta$ CZ $f$ were created by PCR and subcloned into PCS2-MT vector. The deleted 
regions were amino acids 1 to 406 for MT-XSIP1- $\Delta$ NZf, amino acids 408 to 505 for MT-XSIP1- $\Delta$ SBD, amino acids 507 to 880 for MT-XSIP1- $\Delta$ HDCBS and amino acids 882-1214 for MT-XSIP1- $\Delta$ CZf (see Fig. 1).

To construct pGEM-Sox2, Sox2 was amplified by PCR using the forward primer 5'- TCTGCCAGCCTTTGCTCC-3' and the reverse primer 5'- CACATGTGCGACAGAGGC-3' and cloned into pGEM®-T Easy vector (Promega, Madison, Wis). All constructs were verified by sequencing.

\section{Microinjection and animal cap dissection}

Microinjection was performed in $100 \%$ SS containing $5 \%$ Ficoll. mRNA was synthesized using SP 6 mMESSAGE mMACHINE (Ambion, Austin, Tex) with linearized pCS2-XSIP1 (Eisaki et al., 2000), pCS2-MT-XSIP1, pCS2-MT-XSIP1- $\Delta$ NZf, pCS2-MT-XSIP1- $\Delta$ SBD, pCS2-MT-XSIP1- $\Delta$ HDCBS, pCS2-MT-XSIP1- $\triangle$ CZf and pCS2-NLS-lacZ (Takahashi etal., 2000). Animal caps were dissected at stage 9 and were cultured in $100 \%$ SS containing $0.1 \%$ bovine serum albumin for RT-PCR analysis and wholemount in situ hybridization.

\section{$R T$-PCR analysis and real-time $R T-P C R$}

Total RNA was extracted from Xenopusembryos using Isogen (Nippon Gene, Tokyo, Japan). First-strand cDNA was synthesized using $1 \mu \mathrm{g}$ of total RNA with oligo-(dT) primer and SuperScript ${ }^{\mathrm{TM}}$ II RT (Invitrogen, Carlsbad, Calif). One-twentieth of the cDNA was used as a template for RT-PCR. Real-time RT-PCR was performed on an ABI PRISM 7700 (Applied Biosystems, Foster City, Calif) using SYBR Green PCR Master Mix (Qiagen, Hilden, Germany) according to the QuantiTect SYBR Green Kit instructions. Elongation factor $1 \alpha(E F-1 \alpha)$ was used as an internal control and the relative expression amount of each gene was normalized to the expression amount of EF- $1 \alpha$. The results are averages of 3 independent experiments and error bars indicate SEM. Primer sequences were as follows:

$N-C A M$

forward 5'-CACAAGGGGAACCTAGTG-3' and reverse 5'-CTATTAGAAGGTACCCGC-3';

NRP1

forward 5'-CTGTGAGAGGCCGATCTC-3' and

reverse 5'-GTTCTCTCTACACGAAAC-3';

Vent2

forward 5'-GTTCTTTGGTGTGTACGG-3' and

reverse 5'-GCAGGTAGAGCATCTGAA-3',

$E F-1 \alpha$

forward 5'-TTGCCACACTGCTCACATTGCTTGC-3' and reverse 5'-ATCCTGCTGCCTTCTTTTCCACTGC-3'.

\section{Whole-mount in situ hybridization}

Whole-mount in situ hybridization analysis was performed according to Harland (Harland, 1991). Antisense RNA probes were synthesized with the templates pGEM-Sox2 and pSP73-Xbra (Smith et al., 1991). For linage tracing, NLS-lacZ mRNA was co-injected and the embryos were stained with Red-Gal (Research Organics, Cleveland, Ohio) before in situ hybridization.

\section{Acknowledgements}

We thank Dr Jim Smith for his generous gift of plasmid. This work was supported by Grants-in-Aid for Science Research from the Ministry of Education, Science, Sports, Culture and Technology of Japan and by the International Cooperative Research Project of the Japan Science and Technology Agency.

\section{References}

AGIUS, E., OELGESCHLAGER, M., WESSELY, O., KEMP, C. and DE ROBERTIS, E.M. (2000). Endodermal nodal-related signals and mesoderm induction in Xenopus. Development 127: 1173-83.
AMAYA, E., MUSCI, T.J. and KIRSCHNER, M.W. (1991). Expression of a dominant negative mutant of the fgf receptor disrupts mesoderm formation in Xenopus embryos. Cel/66: 257-70.

CHINNADURAI, G. (2002). Ctbp, an unconventional transcriptional corepressor in development and oncogenesis. Mol Ce//9: 213-24.

COMIJN, J., BERX, G., VERMASSEN, P., VERSCHUEREN, K., VAN GRUNSVEN, L., BRUYNEEL, E., MAREEL, M., HUYLEBROECK, D. and VAN ROY, F. (2001). The two-handed e box binding zinc finger protein sip1 downregulates ecadherin and induces invasion. Mol Cel/7: 1267-78.

EIMON, P.M. and HARLAND, R.M. (1999). In Xenopusembryos, bmp heterodimers are not required for mesoderm induction, but bmp activity is necessary for dorsal/ventral patterning. Dev Bio/216: 29-40.

EISAKI, A., KURODA, H., FUKUI, A. and ASASHIMA, M. (2000). Xsip1, a member of two-handed zinc finger proteins, induced anterior neural markers in Xenopus laevis animal cap. Biochem Biophys Res Commun 271: 151-7.

FUNAHASHI, J., SEKIDO, R., MURAI, K., KAMACHI, Y. and KONDOH, H. (1993) Delta-crystallin enhancer binding protein delta ef1 is a zinc finger-homeodomain protein implicated in postgastrulation embryogenesis. Development 119: 433 46.

FURUSAWA, T., MORIBE, H., KONDOH, H. and HIGASHI, Y. (1999). Identification of ctbp1 and ctbp2 as corepressors of zinc finger-homeodomain factor deltaef1. Mol Cel/ Bio/19: 8581-90.

HARLAND, R.M. (1991). In situ hybridization: An improved whole-mount method for Xenopus embryos. Methods Cell Bio/36: 685-95.

HIGASHI, Y., MORIBE, H., TAKAGI, T., SEKIDO, R., KAWAKAMI, K., KIKUTANI, H. and KONDOH, H. (1997). Impairment of t cell development in deltaef1 mutant mice. J Exp Med 185: 1467-79.

KONDOH, H., UCHIKAWA, M. and KAMACHI, Y. (2004). Interplay of pax6 and sox2 in lens development as a paradigm of genetic switch mechanisms for cell differentiation. Int J Dev Bio/48: 819-27.

NIEUWKOOP, P.D. and FABER, J. (1956). Nomal table of xenopus laevis (daudin). North-Holland, Amsterdam.

NITTA, K.R., TANEGASHIMA, K., TAKAHASHI, S. and ASASHIMA, M. (2004). Xsip1 is essential for early neural gene expression and neural differentiation by suppression of bmp signaling. Dev Bio/275: 258-67.

ONUMA, Y., TAKAHASHI, S., YOKOTA, C. and ASASHIMA, M. (2002). Multiple nodal-related genes act coordinately in Xenopusembryogenesis. Dev Bio/241: 94-105.

PAPIN, C., VAN GRUNSVEN, L.A., VERSCHUEREN, K., HUYLEBROECK, D. and SMITH, J.C. (2002). Dynamic regulation of brachyury expression in the amphibian embryo by xsip1. Mech Dev 111: 37-46.

POSTIGO, A.A. and DEAN, D.C. (1999a). Independent repressor domains in zeb regulate muscle and t-cell differentiation. Mol Cell Biol19: 7961-71.

POSTIGO, A.A. and DEAN, D.C. (1999b). Zeb represses transcription through interaction with the corepressor ctbp. Proc Nat/ Acad Sci U S A 96: 6683-8.

POSTIGO, A.A., DEPP, J.L., TAYLOR, J.J. and KROLL, K.L. (2003). Regulation of smad signaling through a differential recruitment of coactivators and corepres sors by zeb proteins. Embo J22: 2453-62.

SASAI, Y. (2001). Roles of sox factors in neural determination: Conserved signaling in evolution? Int J Dev Bio/45: 321-6.

SEKIDO, R., MURAI, K., FUNAHASHI, J., KAMACHI, Y., FUJISAWA-SEHARA, A., NABESHIMA, Y. and KONDOH, H. (1994). The delta-crystallin enhancerbinding protein delta ef1 is a repressor of e2-box-mediated gene activation. $\mathrm{Mol}$ Cell Bio/14: 5692-700.

SMITH, J.C., PRICE, B.M., GREEN, J.B., WEIGEL, D. and HERRMANN, B.G. (1991). Expression of a Xenopus homolog of Brachyury ( $T$ ) is an immediateearly response to mesoderm induction. Cel/67: 79-87.

TAKAGI, T., MORIBE, H., KONDOH, H. and HIGASHI, Y. (1998). Deltaef1, a zinc finger and homeodomain transcription factor, is required for skeleton patterning in multiple lineages. Development 125: 21-31.

TAKAHASHI, S., YOKOTA, C., TAKANO, K., TANEGASHIMA, K., ONUMA, Y., GOTO, J. and ASASHIMA, M. (2000). Two novel nodal-related genes initiate early inductive events in Xenopus nieuwkoop center. Development 127: 5319 29.

TANEGASHIMA, K., YOKOTA, C., TAKAHASHI, S. and ASASHIMA, M. (2000). 
Expression cloning of xantivin, a Xenopuslefty/antivin-related gene, involved in the regulation of activin signaling during mesoderm induction. Mech Dev 99: 314.

VANGRUNSVEN, L.A., MICHIELS, C., VANDE PUTTE, T., NELLES, L., WUYTENS, G., VERSCHUEREN, K. and HUYLEBROECK, D. (2003). Interaction between smad-interacting protein-1 and the corepressor c-terminal binding protein is dispensable for transcriptional repression of e-cadherin. J Biol Chem 278: 26135-45.

VAN GRUNSVEN, L.A., SCHELLENS, A., HUYLEBROECK, D. and VERSCHUEREN, K. (2001). Sip1 (smad interacting protein 1) and deltaef1 (delta-crystallin enhancer binding factor) are structurally similar transcriptional repressors. J Bone Joint Surg Am 83-A Suppl 1: S40-7.

VAN GRUNSVEN, L.A., TAELMAN, V., MICHIELS, C., OPDECAMP, K., HUYLEBROECK, D. and BELLEFROID, E.J. (2006). Deltaef1 and sip1 are differentially expressed and have overlapping activities during Xenopus embryogenesis. Dev Dyn 235: 1491-500.
VERSCHUEREN, K., REMACLE, J.E., COLLART, C., KRAFT, H., BAKER, B.S. TYLZANOWSKI, P., NELLES, L., WUYTENS, G., SU, M.T., BODMER, R. et al. (1999). Sip1, a novel zinc finger/homeodomain repressor, interacts with smad proteins and binds to 5 '-cacct sequences in candidate target genes. JBiolChem 274: 20489-98.

YOSHIMOTO, A., SAIGOU, Y., HIGASHI, Y. and KONDOH, H. (2005). Regulation of ocular lens development by smad-interacting protein 1 involving foxe3 activation. Development 132: 4437-48.

Received: 1st September 2006 Reviewed by Referees: 4th October 2006 Modified by Authors and Accepted for Publication: 21st November 2006 Published Online: 16 May 2007 Edited by: Makoto Asashima 


\section{The Spemann-Mangold}

\section{Organizer}

Edited by Eddy M. De Robertis and Juan A réchaga

Preface

by E.M. DeR obertis and J. A réchaga

HERITAGE OF THE 1924 ARTICLE BY HANS SPEMANN AND HILDE MANGOLD

Introducing the Spemann-Mangold organizer: experiments and insights that generated a

key concept in developmental biology

by $K$. Sander and P. Faessler

Induction of embryonic primordia by implantation of organizers from a different species

Reprint of the original 1924 article by $\mathrm{H}$ ans Spemann and $\mathrm{H}$ ilde $\mathrm{M}$ angold, translated into

English by Viktor $\mathrm{H}$ amburger

Developmental biology of amphibians after $\mathrm{H}$ ans Spemann in Germany

by H. Grunz

Spemann's heritage in Finnish developmental biology by L. Saxén

Spemann's influence on Japanese developmental biology

by M. A sashima and T. Okada

Contribution of the Belgian school of embryology to the concept of neural induction by the organizer

by $\mathrm{H}$. Alexandre

Contrasting influences of the organizer and induction concepts on the scientific activity of French embryologists

by J.-C. Beetschen and A.-M. Duprat

Consequences of the Spemann-Mangold organizer concept for embryological research in Russia: personal impressions

by A.T. M ikhailov and N.A. Gorgolyuk

The organizer concept and modern embryology: Anglo-American perspectives by $T$. $H$ order

THE ORGANIZER CONCEPT: OVERVIEWS AND THEORETICAL APPROACHES

Evolution of the organizer and the chordate body plan by J. Gerhart

Continuity and change: paradigm shifts in neural induction by S. Gilbert

Formation and maintenance of the organizer among vertebrates by $K$. Joubin and C.D. Stern

O rganizer and axes formation as a self-organizing process by H. M einhardt

ORGANIZER RESEARCH TODAY

Molecular mechanisms of cell-cell signalling by the Spemann-Mangold organizer by E.M. De Robertis, O. Wessely, M. Oelgeschläger, B. Brizuela, E. Pera, J. Larraín, J. A breu and D. Bachiller

Formation of a functional morphogen gradient by a passive process in tissue from the early Xenopus embryo

by N. M CD owell, J.B. Gurdon and D.J. Grainger

A study of Xlim1 function in the Spemann-Mangold organizer

by L. Kodjabachian, A.A. Karavanov, H. Hikasa, N.A. Hukriede, T. A oki, M. T aira and I.B. Dawid

Making mesoderm - upstream and downstream of Xbra by J. Smith

Regulation of convergent extension in Xenopus by Wnt5a and Frizzled-8 is independent of the canonical Wnt pathway

by J.B. Wallingford, K.M. Vogeli and R.M. H arland

Generation of the germ layers along the animal-vegetal axis in Xenopus laevis by H. Yasuo and P. Lemaire

Dickkopf 1 and the Spemann-Mangold head organizer by C. Niehrs, O. Kazansakaya, W.Wu, and A. Glinka

Siamois cooperates with TGF $\beta$ signals to induce the complete function of the SpemannMangold organizer

by M.J. Engleka and D. S. Kessler

\section{ORDER FORM}

I would like to order cop(y/ies) of the Int. J. Dev. Biol. Special Issue “The Spemann-Mangold Organizer” (Vol. 45, N 1)

at US\$ 70 or Euro $€ \overline{70}$ per copy (including post and packaging). Total to be charged: US\$ / Euro $€$ (please specify currency)

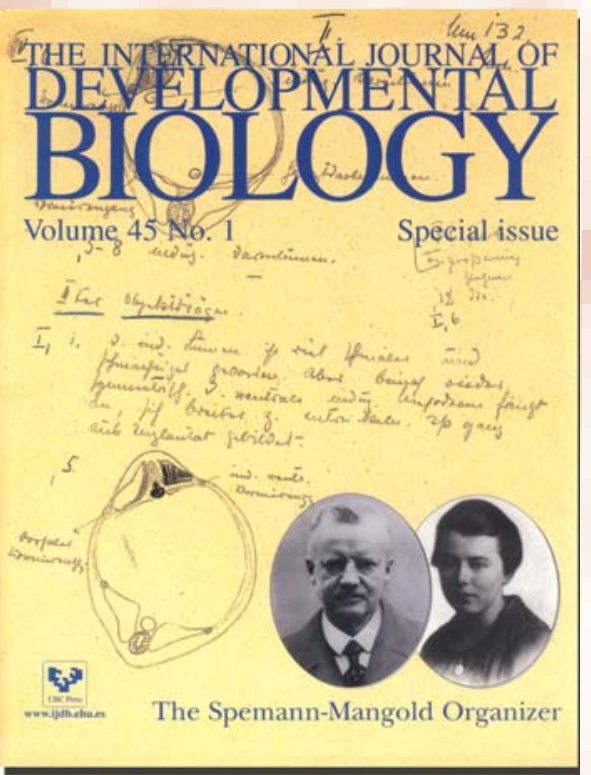

The Spemann-Mangold organizer: the control of fate specification and morphogenetic rearrangements during gastrulation in Xenopus by T. B ouwmeester

Functional analysis of the Xenopus frizzled 7 protein domains using chimeric receptors by R.K. Swain, A. M edina and H. Steinbeisser

Fox (forkhead) genes are involved in the dorso-ventral patterning of the Xenopus mesoderm

by H. El-H odiri, N. Bhatia-Dey, K. Ken yon, K. Ault, M. Dirksen and M. Jamrich

In vitro induction systems for analyses of amphibian organogenesis and body patterning by T. Ariizumi and M. Asashima

The avian organizer

by T. B oettger, H. Knoetgen, L. Wittler and M. Kessel

Nodal signaling and the zebrafish organizer by A.F. Schier and W.S. T albot

The role of the homeodomain protein Bozozok in Zebrafish axis formation by $L$. Solnica-K rezel and W. Driever

Role of the anterior visceral endoderm in restricting posterior signals in the mouse embryo

by A. Perea-Gomez, M. Rhinn and S. -L. Ang

Roles of Sox factors in neural determination: conserved signaling in evolution? by Y. Sasai

G etting your head around $H$ ex and $H$ esxl : forebrain formation in mouse by J.P. M artínez Barbera, R.S.P. Beddington

The role of 0 tx 2 in organizing the anterior patterning in mouse by A. Simeone and D. A campora

Defects of the body plan of mutant embryos lacking Lim1, 0 tx2 or $\mathrm{Hnf3} \beta$ activity by S.J. Kinder, T.E. T sang, S.-L. Ang, R.R. Behringer and P.P.L. T am

0 tx2 and $\mathrm{Hnf} \beta$ genetically interact in anterior patterning by 0 . Jin, K. H arpal, S.L. Ang and J. Rossant

The isthmic organizer and brain regionalization by S. M artínez

Early neurogenesis in amniote vertebrates by N. Le Douarin

\section{ORDER BY}

Web: http://www.intjdevbiol.com

E-mail: ijdb@ehu.es (include the information indicated above)

FAX: $\quad+34-94-601-3266$

FAX: $+34-94-601-3266$

The International Journal of Developmental Biology

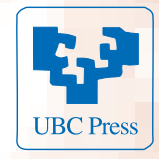

UBC Press - Editorial Service University of the Basque Country E-48940 Leioa, (Vizcaya)

SPAIN 